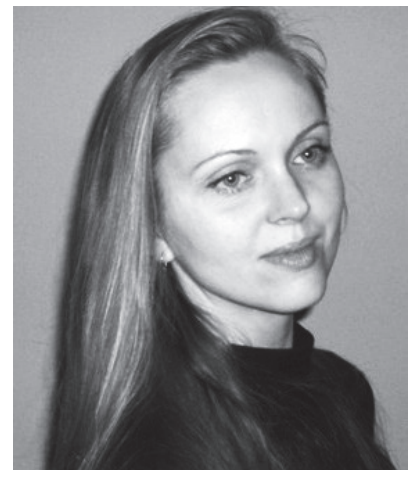

Ernesta Molotokienè - humanitarinių mokslų (filosofija) daktarè, Klaipėdos universiteto Humanitarinių mokslų fakulteto Filosofijos ir kultūrologijos katedros lektorè.

Moksliniai interesai: filosofijos istorija, postfenomenologija, mediju filosofija.

Adresas: Herkaus Manto g. 84, LT-92294 Klaipėda.

El.paštas: irama@inbox.lt.

Ernesta Molotokienè: PhD in Humanities (Philosophy), Lecturer of Department of Philosophy and Cultural Studies at the Faculty of Humanities in Klaipeda University.

Research interests: history of philosophy, post-phenomenology, media philosophy.

Address: Herkaus Manto g. 84, LT-92294 Klaipeda.

E-mail: irama@inbox.lt.

\title{
Ernesta Molotokienè
}

Klaipédos universitetas

\section{PRAMOGŲ PASAULIO „TEATRAS “ KAIP MEDIJUOTOS VISUOMENÉS PROBLEMA}

\begin{abstract}
Anotacija
Straipsnyje analizuojama pramogų pasaulio „teatras“ kaip medijuotos visuomenès problema. Šiuolaikinę Vakarų visuomenę galima vadinti medijuota visuomene dẻl stipraus naujų, globalių medijų sukeliamo poveikio. Tokiomis sąlygomis visuomenè, kasdienis gyvenimas ir kultūra vis dažniau interpretuojami naudojant teatro modelị ir metaforas. Teatras tampa viena esminiu šiuolaikinès Vakarų visuomeninès sampratos kategorijų, pavyzdžiui, vartojant tokias sąvokas, kaip simuliacijos mechanizmu valdoma visuomenè arba spektaklio visuomené. Būtent dèl naujųju - skaitmeninių mediju, ypač interneto, plataus paplitimo Vakarų visuomenèje paskutiniaisiais dešimtmečiais išaugo populiariosios kultūros vartojimas, galima sakyti, prasidèjo pramogu pasaulio era. Straipsnyje analizuojamas pramogu pasaulio reiškinys: jo geneze, struktūra, poveikis visuomenei. Keliamas tikslas: ištirti „pramogų pasaulio“ reiškinio masinio paplitimo priežastis ir tendencijas šiuolaikinejje Vakarų kultūroje kaip neatsiejamą technologinio naujųjų medijų proveržio rezultatą. Analizuojant pramogu pasaulio reiškinị, siekiama: 1) ištirti pramogų pasaulio, kaip kultūrinio reiškinio, genezę, priežastis, tikslus, kritiškai reflektuojant pramogų pasaulio siūlomas mąstymo, gyvenimo būdo formas; 2) atskleisti pramogų pasaulio struktūrą XXI a. „spektaklio“ visuomenėje; 3) analizuoti mediju įtaką pramogu pasaulio dominavimui.

PAGRINDINIAI ŽODŽIAI: pramogų pasaulis, naujosios medijos, spektaklio visuomenè, tikrovè.
\end{abstract}

\section{Abstract}

The article deals with the "theater" of entertainment world as issue of mediated society. Modern Western society can be called a mediated society for a strong impact of new, global media. Under these conditions, society, culture and everyday life is increasingly interpreted using a model of theatre and theatrical metaphors. Theatre is becoming one of the key concepts of the modern Western social categories, such as the use of concepts as simulation or society of the spectacle. Regarding to the wide spread of the new - digital media, especially the Internet, in recent decades 
of Western society, has increased the consumption of popular culture, one might say, began the era of the entertainment world. This study - one of the first attempts to analyze the philosophical Lithuania entertainment world phenomenon: the genesis, structure, impact on society. This article analyzes the phenomenon of entertainment world: its genesis, structure, impact on society. The objective: to explore the causes and trends of mass spread of the phenomenon of entertainment world in contemporary Western culture as an integral part of a technological breakthrough result of new media. The analysis of the phenomenon of entertainment world aims to: 1) explore genesis, causes and objectives of the world of entertainment as a cultural phenomenon and to reflect critically its forms of thinking and lifestyle; 2) reveal the structure of the entertainment world in twenty-first century society of the spectacle; 3 ) analyze the influence of the media impact to the entertainment world.

KEY WORDS: world of entertainment, new media, society of the spectacle, reality.

DOI: http://dx.doi.org/10.15181/rh.v17i1.1158

I va d a s

$\mathrm{XX}$ a. antrojoje pusejje medijos igauna vis daugiau reikšmès mūsų asmeniniam ir socialiniam gyvenimui ir daro milžinišką ittaką šiuolaikinei socialinei ir ontologinei tikrovei. Šiuolaikinę Vakarų visuomenę galima vadinti medijuota visuomene dèl stipraus naujų, globalių medijų sukeliamo dažnai iškreipto realybès suvokimo poveikio. Tokiomis sąlygomis visuomenė, kasdienis gyvenimas ir kultūra vis dažniau interpretuojami naudojant teatro modelį ir metaforas. Teatras tampa viena esminių šiuolaikinès Vakarų visuomeninės sampratos kategorijų, pavyzdžiui, vartojant tokias sąvokas, kaip simuliacijos mechanizmu valdoma visuomenè arba spektaklio visuomené. Būtent dèl naujųiu - skaitmeninių medijų, ypač interneto, plataus paplitimo paskutiniaisiais XX a. dešimtmečiais išaugo populiariosios kultūros vartojimas, galima sakyti, prasidejo pramogų pasaulio era. Pramogu pasaulio supratimui teatro modelis yra labai naudingas, jis padeda atskleisti sudètingą, daugiasluoksnị, neautentišką jo pobūdị. Tačiau vienu pagrindinių sąmoningai ịtvirtintų pramogų pasaulio principų išlieka aiškios ribos tarp realybès ir spektaklio nebuvimas. O tai, atitinkamai, garantuoja nesustabdomą pramogų pasaulio vaizdų invaziją i žmogaus kasdienybę ir jų tapimą neatskiriama šiuolaikinio žmogaus gyvenimo dalimi. Straipsnyje, remiantis Theodoro Adorno, Maxo Horkheimerio ir Walterio Benjamino esminemis pramogų industrijos susiformavimo teorinemis prielaidomis, Guy Debordo spektaklio visuomenès diagnostinėmis ịžvalgomis, Ervingo Goffmano dramaturgine visuomenès, kaip teatro modelio, analize bei Jeano Baudrillardo medijų poveikio kritika, analizuojamas pramogų pasaulio teatrališkumo reiškinys medijuotoje visuomenèje kaip tokio tipo visuomenès problema, siekiant geriau suprasti įvairiais medijiniais kanalais transliuojamo pramogų pasaulio funkcionavimą.

Šio tyrimo objektas: ,pramogų pasaulis“ ir medijų įtaka „pramogų pasaulio“, kaip teatrališkos alternatyvios tikrovès, XXI a. dominavimui. 
Tikslas: ištirti „pramogu pasaulio“ teatrališkumo reiškinį kaip medijuotos visuomenės problemą, įvedant lyginamąią teatro koncepto analogiją kaip metodinị įrankị, siekiant atskleisti šio reiškinio masinio paplitimo priežastis naujųju mediju proveržio kontekste ir tendencijas šiuolaikinejje Vakarų (taip pat ir Lietuvos) kultūroje, bei pasiūlyti konceptualius galimo veikimo modelius.

Uždaviniai: 1) ištirti pramogu pasaulio, kaip kultūrinio reiškinio, genezę, priežastis, tikslus, kritiškai reflektuojant pramogų pasaulio siūlomas mąstymo, gyvenimo būdo formas; 2) atskleisti pramogų pasaulio struktūrą XXI a. „,spektaklio“ visuomenèje, remiantis Guy Debordo kritine visuomenès analize; 3) išanalizuoti medijų ịtaką „dramaturginei“ pramogų pasaulio struktūrai ir dominavimui, remiantis Ervingo Goffmano visuomenès, kaip teatro modelio, analize ir Jeano Baudrillardo kritine medijų teorija; 4) pasiūlyti konceptualius galimo veikimo modelius ,aktyviam“ arba „pasyviam“ pramogu pasaulio vartotojui.

Naujumas ir aktualumas: pramogu pasaulio „invazijos“, pasitelkus naująsias medijas, reiškinys, vis agresyviau plintantis ir tiesmukai primetantis tam tikras vartotojiško mąstymo strategijas, būdamas labai patogus tarpdisciplininėms studijoms, pastaruoju metu sulaukia nemažai užsienio šalių tyrèjų dèmesio, tačiau tiek užsienio šalių, tiek Lietuvos filosofiniame diskurse stokojama išsamesnès ir konkretesnès analizès, ypač šiame straipsnyje pasirinktu „pramoguc pasaulio“ ir teatro koncepto lyginamuoju aspektu. Šis tyrimas aktualiai prisideda prie tarpdiscipliniškai svarbios „pramogu pasaulio“ reiškinio, kuris tikrąja to žodžio prasme tampa vis labiau matomas, demonstratyvus, problemos filosofinès refleksijos, siekiant geresnio šio reiškinio genezès, struktūros, funkcionavimo ir poveikio visuomenei supratimo.

Metodai: atliekant tyrimą, taikomi kritinès analizės, lyginamosios analizės, teorinès rekonstrukcijos teksto interpretavimo metodai.

\section{Pramogų pasaulis: genezè, priežastys, tikslai}

Pramogos kaip bet kokia žmogaus veikla, teikianti malonumą, siekia seniausius laikus - žmogaus, kaip racionalios būtybès, priešistorę. Viena iš žmonijos civilizacijos istorijos sudedamųjų dalių yra pramogų kultūros istorija. Vakarų kultūros istorijoje rasime nemažai tyrimų, skirtų atskirų epochų laisvalaikio malonumams analizuoti. Vienas svarbiausių dalykų, susijusių su pramogų reiškiniu, yra tai, kad norint „pramogauti“, reikia turèti laisvo laiko nuo darbo, skirto būtiniesiems poreikiams patenkinti. Neretai už alinantị darbą gautas atlyginimas skirtingų epochų žmonių būdavo skiriamas pramogoms, t. y. sumokamas už malonumus kaip atpildą ir kompensaciją už darbą.

Šią darbo, kaip būtinų poreikių patenkinimo, veiklą ir pramogas (malonumus), kaip trokštamą laisvalaikio užsièmimą, itin tiksliai atskleidžia senovės Ro- 
mos imperijoje plačiai paplitusi formuluotè: panem et circenses (,duonos ir žaidimu“"). Tačiau tik nuo XX a. antrosios pusès pramogos tampa koncentruotu keleto prodiuserinių Hollywoodo ir JAV kompaniju produktu, masiškai eksportuojamu ì pasaulinę rinką. Būtent JAV pramogų industrijos monopolis, produkuojantis laisvalaikio malonumų schemas, tampa dominuojančiu tenkinant ir formuojant vidurinės klasės malonumus. Prie komercinės JAV prodiuserinių kompanijų sẻkmès prisidèjo ir technologinis naujųu medijų proveržis, kuris, galima sakyti, lèmé masini hollywoodinès produkcijos vartojimą: TV, o vèliau ir interneto bei išmaniųju skaitmeninių technologijų masinis paplitimas pažangiose pasaulio valstybėse palaiko pramogų industriją, o jos produkuojami gyvenimo įvaizdžiai, modeliai, vertybès, net svajonès tampa visuotinai trokštamu produktu, todèl šiandien galima kalbėti apie pramogų pasauli kaip atskirą kultūros segmentą, darantį didžiulę ịtaką daugybei žmonių. Susirūpinimą kelia vis agresyvejjantys prodiuserinių kompanijų metodai, taikomi „kuriant“ dažnai menkavertę produkciją, kuria siekiama bet kokia kaina prikaustyti tokios produkcijos vartotojo dẻmesį: įvairūs TV šou ir projektai, komercinio kino produkcija ir t. t. garantuoja manipuliaciją staigiomis emocinėmis reakcijomis, nepretenduojant ị refleksiją. Pagrịstai galime kelti klausimą: kokios pagrindinès priežastys lèmẻ ir tebelemia tokią pramogų pasaulio vaizdinių invaziją?

Bene pirmąją nuoseklią šių priežasčių refleksiją galime rasti Frankfurto mokyklos atstovy Theodoro Adorno, Maxo Horkheimerio ir Walterio Benjamino darbuose. XX a. antrojoje pusėje daugelyje Vakarų visuomeniu susiformavus

Etimologiškai medijos suprantamos kaip įtarpintas informacijos perdavimas (pavyzdžiui, raštas: informacija perduodama tekstiniu pavidalu, tarpiškai. Tačiau vienas žymiausių medijų teorijos klasikų - Marshallas McLuhanas (Kaip suprasti medijas, 2003) ir jo sekèjai laikosi pozicijos, kad medijos yra ir tam tikri žmogaus kūno organai, susiję su jusline išorinio pasaulio pagava: akys, ausys, rankos, liežuvis, nosis. Nuosekliai laikantis šio požiūrio, galima kelti klausimą: ar neuronai, kuriais sklinda informacija, taip pat yra medijos? Teigiamo atsakymo atveju būtų galima teigti, kad visa be išimties informacija, kuria disponuoja žmogaus smegenys, yra medijuota, kitaip sakant, įtarpinta. Masiškai plintant elektroninėms komunikavimo priemonèms (TV, spauda, radijas, internetas) akademiniame diskurse, o vèliau ir plačiojoje visuomenejje, imama vartoti mass media sąvoka. Tačiau ilgainiui skaitmenizacijos procesų sklaida, susijusi su globalios interneto erdvès sukūrimu, internetą diferencijuoja iš kitų medijų kaip vieną, unikalią, analogo neturinčią ir visas kitas medijas integruojančią mediją. Dažniausiai, kalbant apie internetą, vartojama Levo Manovichiaus pasiūlyta naujųjų medijų sąvoka, akcentuojant kitokị informacijos organizavimo internete principą, lyginant su vadinamosiomis senosiomis medijomis, arba massmedia: ,„<...> dabar esame prasidejjusios naujųju medijų revoliucijos įkarštyje, kai visa mums žinoma kultūra pereina prie kompiuteriu medituojamų gamybos, platinimo ir komunikacijos formų (Manovich 2009, 90), taip pat: „< ..> naujosios medijos reprezentuoja dviejų atskiru istorinių trajektorijų - kompiuterijos ir medijų technologijų susiliejimą“ (ibid.). Dabartiniame europietiškame-amerikietiškame mediju teoretikų tyrimų kontekste neretai vartojamos visos minètos sąvokos arba tiesiog sąvoka „medijos“, kuria dažniausiai apibrèžiama dominuojanti, visaapimanti interneto medija ir su ja susiję tyrimai. 
naujo tipo ekonomikai, paremtai laisva rinka ir neribotu kapitalo kaupimu, pamažu vyko ir tebevyksta gamybos, kultūros ir meno sintezès procesas, kada kultūra virsta masinio vartojimo preke. Šiuos procesus stipriai greitina naujų masinio naudojimo technologijų plitimas, kuris spartina ir masinį kultūros vartojimą. W. Benjaminas savo esė „Meno kūrinys mechaninès reprodukcijos amžiuje“ $(1936)^{2}$ argumentuoja, kad reprodukavimo technologija, pritaikyta pirmiausia fotografijoje ir kine XIX a., meno kūrinius padaro prieinamus masiniam vartojimui, o tai lemia meno reikšmės ir vertès transformacijas: menas vis labiau taikosi prie vartotojų (užsakovų) poreikių, o pati meno kūrinių reprodukavimo technologija stimuliuoja kūrybą, kuri gali būti reprodukuojama. Būtent fotografija, anot W. Benjamino, kaip atvaizdas, panaikina skirtumą tarp originalo ir kopijos. Kalbėdamas apie kino meną, W. Benjaminas pabrèžia, kad kino kūrimo technologija suaktyvina, formuoja visai kitokius ịpročius negu teatras, kur žiūrovai identifikuojasi su aktoriumi, o kine žiūrovai yra stebėtojai, nes jų pozicija yra tokia pati kaip ir kameros. Kaip tik todèl, anot W. Benjamino, žiūrovai, stebintys filmą, yra aktyvūs, nes filmo žiūrèjimas keičia suvokimo lauką. Kamera šiuo požiūriu priartina ir išryškina plika akimi šiaip jau nepastebimas detales ${ }^{3}$. Tačiau dèl skaitmeninių-elektroninių komunikacijos technologijų (vadinamųjų medijų) proveržio ir plètros paskutiniaisiais dešimtmečiais, galima sakyti, kad „kameros“ nebeįmanoma išjungti.

W. Benjamino įžvalgas pratęsia Th. Adorno ir M. Horkheimeris bendrame veikale Dialectic of Enlightenment (1947) ${ }^{4}$, laikydamiesi pozicijos, kad pirmiausia pati kultūra tampa industrinès gamybos sritimi ir funkcionuoja kaip kultūros prekių rinka. Šis masinès kultūros industrijos supratimas, kuri plètojo W. Benjaminas, Th. Adorno ir M. Horkheimeris, apima gana plačią sriti - nuo masinés kultūros serijinių gaminių iki aukštojo mokslo teikiamų paslaugų. XX a. populiarusis menas, anot Th. Adorno ir M. Horkheimerio, yra integrali industrinio kapitalizmo dalis, orientuota į masinį vidutinybių skonị, todèl, kaip ir bet kuri prekè, naujausiomis technologijomis kuriama meno produkcija privalo pataikauti vartotojų skoniui ir patenkinti vartotojų (užsakovų) poreikius. Vienas esminių industrinio kapitalizmo perejimo į vartojimo kapitalizmą bruožų yra nykstanti skirtis tarp populiariosios / masinès (arba popkultūros) ir aukštosios kultūros. Dèl gana greito kūrimo proceso ir komercinès sẻkmès viena pagrindinių masiš-

2 Straipsnyje naudojamas 1979 m. ese leidimas: Benjamin W. ,The work of art in the age of mechanical reproduction“. Illuminations. Glasgow, Fontana/Collins, 1979.

3 Ši kameros aspektą puikiai iliustruoja Michelangelo Antonioni kino filmas „Blow-Up“ („Fotopadidinimas“) (1966), kuriame atskleidžiama tikrovės „demaskavimo“ mechanizmas ir su tuo susijusi suvokimo lauko transformacijos problema.

4 Straipsnyje naudojamas 2002 m. veikalo leidimas: Adorno W. Th., Horkheimer M. Dialectic of Enlightenment. Stanford: Stanford University Press, 2002. 
kai vartojamų meno formų XX a. tampa kinas ir, regis, iki pat šių dienų neužleidžia savo pozicijų.

Populiariosios ir pramogų kultūros tyrinètojas Harvey B. Feigenbaumas teigia, kad: „Vienas svarbiausių tarptautinès rinkos elementų yra kino filmų ir TV šou produkcija. Po aviacijos, JAV kino produkcija yra didžiausia prekių eksporto užsienio rinkoms lyderé“ (Feigenbaum 2007, 372). Panašu, kad prodiuserinès Hollywoodo ir JAV kino kompanijos tinkamu laiku surado ir vartotojams pasiūlè masinančią, gundančią prekę: virtualų reginį / prekę / pramogą. Todèl būtent su Hollywoodo kino produkcija XX a. sietinas „pramogu pasaulio“ industrijos gimimas. Stephenas J. Rosas teigia, kad: „Pramogų kultūros kosmopolitiškumas užkoduotas XIX a. pirmosios pusès nebyliojo kino atsiradimo ir sèkmès istorijoje: ši pramoga buvo skirta daugiausia JAV imigrantams - daugiakalbei darbo klasei ir jų interesams“ (Ros 1998, 86). JAV pramogų industrija produkuoja schemas, kurios integruojamos į skirtingas visuomenes, todèl, anot S. J. Roso, galima pagrịstai kalbèti apie bendrą pramogu pasaulio modeli. Tačiau S. J. Rosas nepakankamai įvertina pramogų pasaulio reiškinio dabartinèje Vakarų kultūroje mutavimo ir / arba transformacijos aspektus: bendra pramogu pasaulio organizavimo schema, orientuota ị komercinę sèkmę, dažnai skirtingose kultūrose „pripildoma“" specifinio turinio, savitų niuansų, todèl sąlygiškai galima kalbèti apie, pavyzdžiui, Lietuvos, Prancūzijos, Vokietijos pramogų pasaulius ir jų funkcionavimo panašumus ir skirtumus. Tačiau akivaizdu, kad lyderès pozicijas, kuriant didžiausio biudžeto pramoginę kino ir televizijos produkciją, tvirtai užima JAV, diktuojanti savas pramogų pasaulio organizavimo taisykles.

\section{Pramogu pasaulio struktūra „spektaklio“ visuomeneje}

Pramogu pasauliui vis labiau tampant kasdienio žmogaus gyvenimo dalimi, kada išsivysto tam tikra priklausomybè nuo lengvai atpažistamais, „artimais“ tapusių vaizdinių vartojimo (domimasi TV ir kino žvaigždžių gyvenimais, todèl, savo ruožtu, prodiuserinės kompanijos siekia „nenuvilti“ vartotojų, nuolat produkuodamos pikantiškas, skandalingas žvaigždžiu gyvenimo detales ir t. t.), pamažu nyksta riba tarp tikrovès ir fikcijos.

Vienas pirmųu šio pavojingo proceso analitiku - Guy Debordas savo veikale Spektaklio visuomene $(1967)^{5}$ bando apmąstyti vizualinès manipuliacijos visuomenès lūkesčiais mechanizmus ir pateikia vadinamosios „spektaklio“ visuomenès kritiką. Spektaklis, anot G. Debordo, yra nauja kapitalo generavimo ir visuomeninių santykių forma: vietoje gamybinio kapitalo išplètojama kultūrinè

5 Straipsnyje naudojamas 2006 m. šio veikalo leidimas: Debord G. Spektaklio visuomene. Vilnius: Kitos knygos, 2006. 
industrija, žiniasklaida ir populiarioji kultūra: „Spektaklis yra tokio kaupimo lygio kapitalas, kad tampa reginiu“ (Debord 2006, 34). Anot G. Debordo, vartotojiškoje visuomenejje kapitalas nustojo būti neregimas procesas, priešingai, jis virsta regima iliuzija, igyja savo „veidą“, kuriuo jis atpažistamas, o tuo meistriškai naudojasi pramogu industrijos ir reklamos kūrejai. Tokiu atveju pats pramogu pasaulis, kaip „spektaklis“, ir yra industrija, gaminanti pridètini kapitalą.

Ši pramogų pasaulio aspektą pastebi ir žymus prancūzų sociologas, poststruktūralistas Pierre Bourdieu veikale İvadas $\dot{i}$ refleksyviaja sociologija (1992) pabrèždamas, kad populiarioji kultūra gamina ne tik pridètinị, bet ir simbolini kapitalą, akumuliuojantị populiarumą, galią ir pelną. Sceninè teatro aplinka, kaip pažymi G. Debordas, tampa kasdienybės dekoracija, transformuodama pati kasdieni gyvenimą, todẻl nebeįmanoma atskirti, kur yra režisuojamas spektaklis, o kur tikras gyvenimas: „Ištisas visuomenių, kuriose viešpatauja modernios gamybos sąlygos, gyvenimas pasireiškia kaip milžiniška spektaklių sankaupa. Tai, kas buvo išggventa tiesiogiai, pasitraukè ị atvaizdavimo sritị““ (Debord 2006, 40). Tai akivaizdžiai matoma pramogu pasaulio žvaigždžiu gyvenimo „kronikose“ arba įvairiuose realybės šou: privatus gyvenimas, paprasčiausia buitis tampa reginiu, pateikiamu masinei vartotojų auditorijai. Populiariosios kultūros tyrinėtoja Kim McNamara pažymi, kad paskutiniaisiais XX a. dešimtmečiais pramogų pasaulio industrija tapo „savitikslè, gerai organizuota sistema ypač dèl paparacių segmento susiformavimo“ (McNamara 2011, 516): būtent paparaciai ,,aptarnauja“ masinio pramogų pasaulio kronikų vartojimo poreikị, sekdami ir fiksuodami kiekvieną žvaigždžiu žingsnį. Masinị vartojimą šiuo atveju garantuoja anksčiau minètas spektaklio „atpažǐstamumas“, kitaip sakant, vartotojai spektaklyje turi atpažinti save, savo ịpročius, gyvenimo būdą ir t. t. Ši savęs atpažinimo schema yra paremta malonumu (tas pats malonumo principas galioja ir tuo atveju, kai „atpažinimas“ neįvyksta: tuomet konstatuojamas vartotojo kitoniškumas nuo pramogų pasaulio aktorių, pranašumas, kuris yra malonus). Kadangi pramogų industrijos siūlomų malonumų spektras vartotojų auditorijai yra labai platus (muzikiniai, vaidybiniai, šokių, dainavimo, talentų projektai, TV ir videožaidimai, filmai, įvairūs šou ir t. t.), praktiškai garantuojama absoliuti šios produkcijos sẻkmè: maksimalus bet kokių vartotojų interesų patenkinimas. Kaip tik todèl prodiuserinès kompanijos bet kokia kaina siekia išlaikyti pramogu pasaulio žvaigždžiu patrauklumą ir tuo pačiu metu išsaugoti vartotojų emocinès įtampos lauką, kada vartotojai palaiko mylimas žvaigždes ir smerkia nemylimas žvaigždes.

Akivaizdu, kad už šio emocinio fono slepiasi rinkodaros ir reklamų strategija: žvaigždžiu reklamuojamos prekès didina jų masinị vardijimą, dar daugiau - pačios žvaigždès tampa komerciškai sẻkmingais reklaminiais veidais. „Spektaklis, anot G. Debordo, - vienu metu pasirodo kaip pati visuomené, kaip visuomenès 
dalis ir kaip vienodinimo instrumentas“ (Debord 2006, 40). Pramoguc pasaulio atveju vienodinimas pasireiškia kaip standartinio gyvenimo būdo produkavimas: tam tikras tipiškas žvaigždžių įvaizdis (išvaizdos standartas), sẻkminga - „svajonių“ buitis: nuosavas prabangus nekilnojamasis turtas, garsūs prekiniai ženklai, „tobulas“ gyvenimo draugas ir / arba „tobuli“ vaikai, prabangūs vakarèliai, egzotiškos kelionès, neribotas laisvalaikis ir t. t. Visa tai formuoja daugeliui trokštamą gyvenimo viziją, „,tikina“ jos realumu, nors kasdienybẻ dažniausiai labai skiriasi nuo pramogų pasaulio žvaigždžių spindesio. G. Debordas teigia, kad: „Visomis savo atskiromis formomis, įkūnijančiomis informaciją ar propagandą, reklamą ar betarpišką pramogų vartojimą, spektaklis sudaro šiuo metu visuomenėje viešpataujantị gyvenimo modelį“ (Debord 2006, 41).

Vienas pagrindinių pramogų pasaulio bruožų po orientacijos į masinį vartojimą yra jo „amžinos dabarties“ mito kūrimas ir palaikymas. Iš esmès tai yra gundymas malonumų amžinybe: žvaigždès nesensta, nemiršta - jos „nepastebimai“ pakeičiamos kitomis. Taip palaikoma pramogų pasaulio vizijos galia, prisidedanti prie amžino spindesio, laimès, lengvumo, sèkmès mitų kūrimo.

Paskutiniaisiais XX a. dešimtmečiais dèl išmaniųju skaitmeninių medijų masinio paplitimo pastebimas kitas labai svarbus pramogu pasaulio bruožas, kada siekiama maksimaliai priartinti pramogų pasaulị prie tikrojo - kasdienio gyvenimo: interaktyvumas. Interneto vartotojai gali kontaktuoti su žvaigždėmis on-line (tiesiogiai). Tam praverčia ir prodiuserinių kompanijų komerciniai projektai: „,susitikimai“ su žvaigždèmis (,Šok su žvaigžde“, „Dainuok su žvaigžde“, „Pusryčiai su žvaigžde“"ir t. t.), kuriais dalis visuomenès skatinama toleruoti ir palaikyti pramogu pasaulio taisykles, tiesiogiai dalyvaujant arba tampant pramogų pasaulio dalimi.

Pastaruoju metu itin aktyviai siūlomos neribotos galimybès tapti pramogu pasaulio žvaigžde: tuo tarsi ịperšama greitai pasiekiama „svajonių“ gyvenimo vizija. Atrodo, kad norint tapti pramogu pasaulio žvaigžde užtenka jausti ritmą, padainuoti vieną dainą ar kokiu nors būdu sugebèti „įdomiai“ pateikti save žiūrovų auditorijai. Taip nebelieka skirties tarp tikrovès ir fikcijos, nes fiktyvūs pramogu pasaulio elementai persismelkia į tikrovę. G. Debordas teigia, kad tokiu atveju: ,$<\ldots>$ tikrove staiga atsiveria spektaklyje, o spektaklis tampa tikrove“ (Debord 2006, 43). Tačiau pagrindinis tokio pramogu pasaulio teatro dominavimo XXI a. vartotojiškoje visuomenejje veiksnys yra masinis naujųjų mediju palitimas ir vartojimas, lemiantis, kad W. Benjamino aprašyta „kamera“ niekada neišsijungia, kitaip sakant, prodiuserinès kompanijos niekada nesiliauja gaminti komerciškai sẻkmingos produkcijos, tampančios trokštama masinès vartotojų auditorijos pramoga. 
3. Mediju ittaka pramogur pasaulio

teatro dominavimui

Šiuolaikinę Vakarų visuomenę galima vadinti medijuota visuomene dèl stipraus naujų, globalių mediju sukeliamo poveikio. „Medijų sprogimas“ siejamas su masiniu skaitmeninių-elektroninių komunikacijos technologiju paplitimu ir vartojimu pasauliniu mastu, prasidejjusiu paskutiniaisiais XX a. dešimtmečiais (tokioms technologijoms priskiriama: šviesolaidinis internetas, planšetiniai kompiuteriai, išmanieji telefonai ir kt.), ir yra vis dar vykstantis procesas, sparčiai veikiantis praktiškai visas žmogaus veiklos formas, todèl šio reiškinio visuotinumas ir plètra yra sudètingas šiuolaikinių medijų teoretikų tyrimo objektas visame pasaulyje: bandoma teoriškai apibrèžti šį kompleksišką reiškinị ir suformuluoti vyraujančių šiuolaikinių medijų teorijų raidos tendencijų futurologinę perspektyvą. Mediju socialinis, politinis, kultūrinis, ekonominis ir technologinis reikšmingumas nuolat dideja, plečiantis interneto ir kompiuterinių tinklų erdvei, stiprejjant globaliesiems idejjų karams, formuojantis pasauliniam informacinių karų skydui ir internetinio valdymo tinklui. Naujosios medijos yra bene svarbiausias veiksnys, lemiantis pramogų pasaulio įvaizdžių ir modelių invaziją, kuri sparčiai tampa neatskiriama kasdienybės dalimi.

Vienas pirmųjų medijų analitikų - žymus prancūzų filosofas Jeanas Baudrillardas savo tyrimuose atskleidžia, kaip naujosios medijos pakeičia socialumą, istoriją, komunikaciją, pasaulèvaizdį, realybę. Medijos vaidina esminį vaidmenị konstatuojant naują istorijos padètị ir visuomenès formą, „,nuopolį“ nuo modernios, industrinès prie postmodernios, simuliacijų epochos. J. Baudrillardo požiūris į medijas, ypač televiziją, neatskiriamas nuo jo simuliacijos teorijos - sparčios ženklu proliferacijos visame socialiniame ir kasdieniame gyvenime sampratos. Medijos J. Baudrillardo filosofineje teorijoje tampa esmine simuliacijos technologija, apversdamos realybès ir reprezentacijos santykius. J. Baudrillardas vartoja ir M. McLuhano įvestas „,karštos“ bei „,vėsios“ medijos sąvokas, tačiau, skirtingai nei M. McLuhanas, J. Baudrillardas „vèsia“ laiko bet kurią dominuojančią mediją. Karštus įvykius medija atšaldo, sunaikina.

Veikale Simuliakrai ir simuliacija $(1981)^{6}$ J. Baudrillardas teigia, kad: „Dabar pasitelkus modelius generuojama tikrovè, neturinti nei kilmès, nei realybės: tai hipertikrove““ (Baudrillard 2002, 7). Visas gyvenimas persikelia ị mediją: „Bet kuriuo atveju virtuali kamera yra mūsų galvose“ (Baudrillard 1996, 26). J. Baudrillardas tokią virtualią medijų technologijų raišką vadina amžinu realybès šou arba, kitaip tariant, nesibaigiančiu teatro spektakliu. Virtualybẻ nebėra reginys, igalinantis refleksiją: „Mes esame nebe žiūrovai, o vaidinantys aktoriai, aktoriai,

6 Straipsnyje naudojama 2002 m. šio leidimo versija: Baudrillard J. Simuliakrai ir simuliacija. Vilnius: Baltos lankos, 2002. 
kurie vis labiau įtraukiami ị šio vaidinimo eigą“ (Baudrillard 1996, 27). Tokia tendencija ypač akivaizdi, pasitelkiant kito žymaus sociologo - Ervingo Goffmano dramaturginę visuomenès, kaip teatro modelio, analizę, pagal kurią, remiantis teatro vaidmens metafora, pabrèžiamas individo tapatinimas su vaidmeniu arba kauke. Remiantis abiejų autorių esminiais teorijų principais, išeitų, kad, viena vertus, pats individas atlieka begalinius socialinius vaidmenis socialineje gyvenimo realybės plotmeje, panašiai kaip ir G. Debordo subjektas (tik pastarasis yra labiau institucinių galios laukų auka), kita vertus, naujosios medijos transliuoja ir papildomai iškreipia šį virtualaus teatro šou. Kaip tik šioje vietoje fiksuojamas esminis lūžis, kada praktiškai nebeįmanoma atskirti realybės nuo fikcijos.

Veikale Savęs pateikimas kasdieniame gyvenime $(1959)^{7}$ E. Goffmanas teigia, kad individų socialinè sąveika remiasi socialinio vaidinimo logika, kurios iš individo tikisi publika. Asmens savimonè (Self) dramaturgijos teorijoje apibrèžiama kaip socialinio gyvenimo scenoje susiformavęs dramaturginès sąveikos padarinys. E. Goffmanas skiria virtualią ir realią tapatybes: kadangi publika neįžvelgia skirtumo tarp virtualios ir realios individo tapatybès, vienas pagrindinių individo siekių tampa valdyti informaciją, kuri neatskleistu publikai jo išskirtinumo. Anot E. Goffmano, asmens identitetas priklauso nuo to, kaip gerai individas geba atlikti savo socialinius vaidmenis ir kaip tiksliai šie vaidmenys atitinka visuomenès (publikos) lūkesčius: „Matome, kad atlikèjo asmeninis fasadas dažnai pasitelkiamas ne tam, kad asmuo galètų išreikšti save taip, kaip norètų, bet tam, kad jo išvaizda bei raiškos būdas vienaip ar kitaip padètų kurti vaizdą scenoje“" (Goffman 2000, 92). Šis pastebejjimas gana taikliai atspindi pramogu pasaulio ,žvaigždžių“ savęs pateikimo publikai (visuomenei) „scenografiją“, kur ịvaizdžio, stiliaus, viešųjų ryšiu ekspertų komandinio darbo metu sukurta „žvaigždè“, kaip personažas, privalo visiškai išpildyti su juo siejamus komercinius lūkesčius. Lietuvos pramogu pasaulyje kurị laiką itin ryškus buvo su tokio tipo „vaidmenų atlikejjais“ arba „,̌vaigždžių“ gamyba siejamas projektas „Olialia pupytės“, vartotoju publikai siūlęs tam tikro, lengvai įsimenamo tipažo atlikèjas (būtinai jaunos, pageidaujama - įvairių skandalu nevengiančios merginos, itin šviesiais plaukais, patobulintomis kūno linijomis, apsinuoginusios ir t. t.). Tokie ir panašūs projektai priversti taikytis prie nepastovaus vartotojų skonio ir augančiu poreikių, paprastai jie būna siejami su įvairiais, tam tikrais atvejais net kriminaliniais skandalais, todèl nepretenduoja ị išliekamąją vertę turinčios produkcijos gamybą. Tad tikslinga įvesti „aktyvaus“ ir „pasyvaus“ pramogų pasaulio vartotojo skirti, siekiant pabrèžti jos sąlyginumą naujųiu mediju poveikio kontekste. Nebūtina „aktyviai“ domètis, sekti, stebèti, komentuoti arba tiesiog dirbti pramogu industrijoje ir išmanyti jos

7 Straipsnyje naudojamas $2000 \mathrm{~m}$. šio veikalo, išversto ị lietuvių kalbą, leidimas: Goffman E. Savęs pateikimas kasdieniame gyvenime. Vilnius: ALK/Vaga, 2000. 
užkulisius, nes dẻl naujųjų medijų dominavimo mūsų kasdienybejje pramogų pasaulio vaizdiniai gali smelktis taip pat ir „pasyviai“, pavyzdžiui, reklamos pavidalu. Kaip tik todèl naujųu medijų ir pramogų industrijos sąveika dabar tokia efektyvi.

J. Baudrillardas teigia, jog pačios masės reikalauja iš medijų reginio, kol lieka nebeaišku, ar medijos veikia mases, ar atvirkščiai. Taigi tokia abipuse sąveika tarp masiu ir informacijos trinamos ribos tarp realybès ir medijos. Tarp kolektyvinès sąmonès ir medijų vyksta implozija - susitraukimas ir vienalaikiškumas. Medijos savo imploziniu pobūdžiu sunaikina komunikaciją ir socialumą. Visuomenè tampa indiferentiškomis masėmis. Medijos simuliuoja socialumą: „Visos mūsų kategorijos įžengè į dirbtinị amžių: jokio noro - tik privertimas žmones norèti; jokio veikimo - tik privertimas žmones veikti; jokio buvimo kažko vertam - tik gavimas kažko, kad būtum ko nors vertas (apskritai - kad būtum reklamos liudininku); jokio žinojimo - tik sužinojimas; ir galiausiai, bet ne menkiausiai, ne tiek mégavimasis, ne tiek malonumo gavimas, kiek privertimas žmones mėgautis, privertimas patirti malonumą“" (Baudrillard 1993, 47). Todèl, anot J. Baudrillardo, dabar, postmodernioje epochoje, lieka tik simuliuoti, pakartoti scenarijus. Kai tik vaizdas išsilaisvina nuo įvykio, jis nebeturi jokio ryšio su tiesa, taigi natūraliai linksta į simuliaciją. „Praeityje, norėdami ką nors parodyti kaip klastotę, sakydavome: 'Tai tik vaidyba!'; 'Tai vien prasimanymas!'; 'Vaidinama prieš kameras!' Dabar galime sakyti:‘Tai tik televizija'.“ (Baudrillard 1994, 55).

Kadangi medijuotoje visuomeneje informacija neturi nieko bendro su reikšme, nes prasmè paprasčiausiai prarandama dèl agresyvaus, bukinančio informacijos, mediju ir žiniasklaidos poveikio, todèl, galima sakyti, kad pramogu pasaulis neprodukuoja jokios prasmès, neturi jokio refleksijai būtino gylio. Žinoma, tokia J. Baudrillardo pozicija yra ambivalentiška, turint galvoje tai, kad visuotinai priimta manyti, jog informacija kuria komunikaciją, vadinasi, tam tikrą pridètinę vertę - prasmę. Tačiau medijuotos visuomenès, besimègaujančios nepertraukiamu informacijos srautu, atveju, yra visai priešingai - vartotojus pasiekianti informacija nebeturi jokio turinio, kitaip sakant, jokios vertės. J. Baudrillardas nurodo dvi šio reiškinio priežastis: 1) medijomis sklindanti informacija vaidina prasmę ir todèl išsisemia, tampa beprasme: taip vyksta simuliacijos, hipertikroviškumo procesas; 2) medijomis sklindanti informacija prisidengia „erzinančiu komunikacijos spektakliu“, siekdama destruktūrizuoti sociumą (Baudrillard 2002, 97-98).

Ypač šie procesai tampa akivaizdūs, kalbant apie pramogų pasaulio dominavimą dabartinèje Vakarų kultūroje, kada nebeįmanoma atskirti fikcijos nuo tikrovès, o prasmès nuo beprasmybès. E. Goffmano įžvalgos, kaip matème, tik sustiprina kritinę J. Baudrillardo poziciją. E. Goffmanas įtikinamai pagrindžia, kad kasdienių kiekvieno mūsų teatrališkų pasirodymų visuomenei tikslas yra ne 
tik tiesioginis konkrečiu interesų siekimas, bet visuomet kartu ir dramaturginis spektaklis, kuriuo siekiama valdyti auditorijai sukeliamą įspūdį. Dramaturginis igudimas, arba visapusiškas vaidmenų įvaldymas, vadinamas susiformavusiu asmens tapatumu, kuris vis dèlto iš esmès tèra fikcija. Šiame beprasmybès kontekste kyla klausimas: ar yra koks nors prasmès pakaitalas, teikiantis atskaitos tašką chaotiškai vykstančiai prasmės implozijai medijose? J. Baudrillardas nurodo, kad: „Anapus prasmès yra žavesys, kuri žadina prasmès neutralizacija ir implozija“ (Baudrillard 2002, 101). Ar pramogu pasaulio vaizdinių, kuriamų mitų vartojimas šiuo atveju gali būti „žavus“ savo visiška beprasmybe? O jeigu vis dar įmanoma reflektuoti šią situaciją, galbūt ji nėra conditio sine qua non?

Tuomet kyla klausimas: kokie tokiomis sąlygomis įmanomi konceptualūs galimo veikimo modeliai? Turint galvoje visą straipsnyje aptartą problemini kontekstą, siūlomi tokie preliminarūs koncepciniai veikimo modeliai: 1) kurti asmenybės (individualų) teatrą - unikalu gyvenimo projektą (komercini arba nekomercinị); 2) būti „interaktyviu“ vykstančio spektaklio stebètoju / vartotoju (kritiškai reflektuoti, dalyvauti pilietinèse akcijose, išsakyti savo nuomonę); 3) būti pasyviu stebètoju / vartotoju (priimti ir vartoti pateikiamą pramoginę produkciją); 4) tapti pramogu pasaulio kūrèju, aktyviu dalyviu, gamintoju ir vartotoju; 5) pasitraukti iš visuomenès / ignoruoti tokio turinio informaciją (,atsijungti nuo tinklo“); 6) kūrybiškai išnaudoti visas galimybes ir tiesiog gyventi pasirinktoje realybejje.

Išvados

1. Su Hollywoodo kino produkcija XX a. sietinas „pramogu pasaulio“ industrijos gimimas. Šiuo metu JAV pramogų industrija produkuoja schemas, kurios integruojamos ị skirtingas visuomenes, todèl galima pagrịstai kalbèti apie bendrą pramogų pasaulio modeli. Tačiau bendra pramogu pasaulio organizavimo schema, orientuota į komercinę sèkmę, dažnai skirtingose kultūrose „pripildoma“ specifinio turinio, savitų niuansų, todèl sąlygiškai galima kalbèti apie, pavyzdžiui, Lietuvos, Prancūzijos, Vokietijos pramogų pasaulius ir jų funkcionavimo panašumus ir skirtumus.

2. Vienas pagrindinių pramogų pasaulio bruožų po orientacijos ị masinị vartojimą yra jo „amžinos dabarties“ mito kūrimas ir „spektaklio“ režimo palaikymas, pasitelkiant naujųjų medijų technologijas. Naujosios medijos yra bene svarbiausias veiksnys, lemiantis pramogu pasaulio i̇vaizdžiu ir modelių invaziją, kuri sparčiai tampa neatskiriama kasdienybės dalimi, pamažu nykstant ribai tarp tikrovès ir fikcijos.

3. G. Debordo, E. Goffmano ir J. Baudrillardo kritinių teorijų esminès išvados paremtos visuomenès kaip begalinio „spektaklio“, „teatro“ ir „šou“, 
trunkančio neapibrèžtame erdvèlaikyje (virtualybėje), charakteristikomis, pabrèžiant visišką realybės sunykimą, kuo, kaip įrodoma straipsnyje, tinkamai pasinaudoja pramogų industrijos kūrejjai, produkuodami banalias, komerciškai sèkmingas „,̌̌vaigždžių“ schemas kaip realybės pakaitalus.

4. Išanalizavus pramogu pasaulio ,teatro“, kaip medijuotos visuomenès problemos, reiškinị, toliau siūlomi galimi konceptualūs veikimo modeliai, esant pramogų pasaulio režimui: 1) kurti asmenybès (individualų) teatrą unikalų gyvenimo projektą (komercinic arba nekomercinị); 2) būti ,interaktyviu“ vykstančio spektaklio stebėtoju / vartotoju (kritiškai reflektuoti, dalyvauti pilietinėse akcijose, išsakyti savo nuomonę); 3) būti pasyviu stebètoju / vartotoju (priimti ir vartoti pateikiamą pramoginę produkciją); 4) tapti pramogu pasaulio kūrèju, aktyviu dalyviu, gamintoju ir vartotoju; 5) pasitraukti iš visuomenès / ignoruoti tokio turinio informaciją (,atsijungti nuo tinklo“); 6) kūrybiškai išnaudoti visas galimybes ir tiesiog gyventi pasirinktoje realybeje.

\section{Literatūra}

Adorno W. Th., Horkheimer M. Dialectic of Enlightenment. Stanford: Stanford University Press, 2002.

Antonioni M. „Blow-Up“ kriminaliné drama. Didžioji Britanija, JAV, 1966.

Baudrillard J. The Illusion of the End. Oxford: Polity Press, 1994.

Baudrillard J. The Perfect Crime. London, New York: Verso, 1996.

Baudrillard J. The Transparency of Evil. London, New York: Verso, 1993.

Baudrillard J. Simuliakrai ir simuliacija. Vilnius: Baltos lankos, 2002.

Benjamin W. „The work of art in the age of mechanical reproduction“. Illuminations. Glasgow, Fontana/Collins, 1979.

Bourdieu P. İvadas ị refleksyviaja sociologija. Vilnius: Baltos lankos, 2003.

Debord G. Spektaklio visuomenè. Vilnius: Kitos knygos, 2006.

Feigenbaum B. H. „Hegemony or diversity in film and television?“ The United States, Europe and Japan: Taylor \& Francis. The Pacific Review. Vol. 20, No. 3. September 2007: 371-396, 2007. Goffman E. Savęs pateikimas kasdieniame gyvenime. Vilnius: ALK/Vaga, 2000.

Manovich L. Naujųų mediju kalba. Vilnius: Mene, 2009.

McLuhan M. Kaip suprasti medijas. Vilnius: Baltos lankos, 2003.

McNamara K. „The paparazzi industry and new media: The evolving production and consumption of celebrity news and gossip websites“. International Journal of Cultural Studies, Sage. 2011: 14-515. Prieiga internetu: http://ics.sagepub.com/content/14/5/515 [žiūrèta 201402 20].

Ros, Stephen J. Working-class Hollywood. Princeton: Princeton University Press, 1998. 


\section{Ernesta Molotokienè}

\section{THE “THEATRE” OF ENTERTAINMENT WORLD AS ISSUE OF MEDIATED SOCIETY}

Sum mary

At the present day the phenomenon of "invasion" of entertainment world is spreading aggressively through new media. The article deals with the "theater" of entertainment world as issue of mediated society. In the second half of the twentieth century media is gaining more and more importance in our personal and social life, and makes a huge impact on contemporary social and ontological reality. The modern Western society can be called a mediated society for a strong impact of new global media and because they are related with distortion of our perception of reality. Under these conditions society, culture and everyday life is increasingly interpreted using the model and metaphors of the theater.

Theatre becomes one of the fundamental concepts of modern Western social categories using the terms such as simulation of reality, performance and other. Regarding to the wide spread of the new digital media, especially the Internet, in recent decades of Western society has increased the consumption of popular culture, one might say, began the era of the entertainment world. Theater model is very important in order to understand the world of entertainment, because it helps reveal his complicated, multi-layered nature. On the other hand, one of the main principles of the world of entertainment remains the lack of clear boundaries between reality and performance. That is why going on an unstoppable invasion of entertainment images to human daily life and they are becoming an integral part of modern human life.

On the basis of essential theoretical assumptions related with emergence of entertainment industry by Theodor Adorno, Max Horkheimer and Walter Benjamin, and of dramaturgical model of society as a theater by Erving Goffman as well as of diagnostic insights related with society of performance by Guy Debord and of criticism of the media impact on society by Jean Baudrillard's in the article are analysed the theatrical phenomenon of entertainment world in mediated society as the kind of problem related with mediated society in order to better understand the functioning of entertainment world.

The task of this article is world of entertainment and media influence of entertainment world that is understood as an alternative theatrical reality of the twenty-first century.

The objective of this article is to investigate the theatrical phenomenon of "entertainment world" as mediated public issue by introducing the comparative 
analogy of theater concept as a methodological tool in order to reveal causes of the global spread of this phenomenon in the context of new media as well as trends in contemporary Western (as well as Lithuania) culture, and offer conceptual models of possible action.

The analysis of the phenomenon of entertainment world aims to: 1) explore genesis, causes and objectives of the world of entertainment as a cultural phenomenon and to reflect critically its forms of thinking and lifestyle; 2) reveal the structure of the entertainment world in twenty-first century society of the spectacle; 3) analyze the influence of the media impact to the entertainment world. The research in this article opens up an interdisciplinary perspective and actually contributes to the complicated phenomenon of entertainment world that becomes increasingly visible and problematical as well as opens up philosophical reflection in order to improve this phenomenon genesis, structure, functioning and impact of public awareness. 